\title{
Meraque/San Jiao of Eastern Medicine in Comparison with the Mesentery System Presented in Western Medicine
}

\author{
Majid Avijgan ${ }^{a} \quad$ Mahtab Avijgan $^{b} \quad$ Firouze Salehzadeh $^{c}$ \\ anfectious Diseases and Persian Medicine Department, and Departments of ${ }^{b}$ Medicine and \\ 'Obstetrics and Gynecology, Isfahan University of Medical Sciences, Isfahan, Iran
}

Keywords

Persian medicine $\cdot$ Traditional Chinese medicine · Gastroenterology · Fascia · Meraque ·

Mesentery · San Jiao · System

\begin{abstract}
Background: In Persian medicine (PM) and traditional Chinese medicine (TCM), there is an ignored space, namely the Meraque/San Jiao (M/S) space, which in our previous article has been described in detail. Recently, there has been a publication about the mesentery system describing it as a new system with a history of no more than 300 years. According to our previous publications, this is a part of the M/S system, which could represent adipose tissue and vessels. The mesentery and the M/S system can be regarded as one system, except that the mesentery system is a section of the integrated system of $\mathrm{M} / \mathrm{S}$ with a history of more than 3,000 years; this is the main topic of this report. Key Message: Comparing the mesentery with the Meraque in PM and the San Jiao in TCM, we can conclude that the M/S is more complete than the mesentery. Based on ancient classical texts of PM, the Meraque system has 6 labyrinths and includes all membranes, the fascia, vessels, adipose tissue, and the gut. In PM and TCM, it has a very important role. We will attempt to modernize the M/S. This leads to new methods in treatment, management, and research of Western medicine.
\end{abstract}

(C) 2017 The Author(s)

Published by S. Karger AG, Basel

\section{Background}

Recently, in The Lancet Gastroenterology and Hepatology, an article on the mesentery system was published, in which the authors claimed that this is a new system of the human body [1]. Simultaneously, our team wrote a letter to the author, Dr. R. Coffey (as a personal 
but public comment on the ResearchGate website). We claimed that the mesentery is not a new system but has a history of probably more than 3,000 years in Persian medicine (PM) and traditional Chinese medicine (TCM).

After 7 months' of reviewing and studying ancient classical text books of PM, we rewrote our letter to the editor of the journal and repeated our idea and theory but received no clear reply. Therefore, we would like to present our idea and theory here for scientific judgment.

\section{History of the Mesentery System}

Although the article on the "mesentery system" [1] was remarkable and presented informative details about this system, it appears to have some flaws and weaknesses compared to similar but more extended systems, such as the Meraque in PM and San Jiao in TCM.

PM (named Tibb-e-Parsi) is, to all intents and purposes, a school of medicine with a history of more than 3,000 years (before the appearance of Islamic and Arab attacks against the Persian emperor). The oldest reference to the mesentery system can be found in the time of Leonardo da Vinci [2, 3]; however, this system is part of a more extended organ in the human body, named Meraque system in PM and San Jiao in TCM, which was presented at least 3,000 years ago [4-7]. This system is rather complicated, and nobody has ever been able to fully describe its location, anatomy, and structure [8-10]. This is the main topic of this brief report.

In fact, we suggested that the Meraque/San Jiao (M/S) system has nearly 6 labyrinths or layers, and the mesentery is only 1 of them. Although the mesentery layer is the most important part of this organ, it cannot carry out all M/S functions alone. Other parts have to be involved in this system, which need to be explained [unpubl. data].

We started studying this organ in 2008 and, to investigate it step by step, published the following studies about Qi production [11], infrastructure of the human body [12], primo vascular system as a basis for Qi production which originates from the polar body [13], San Jiao as a real or false space [14], triple energizer (San Jiao) as an actual virtual organ in traditional medicine [15], a practical workshop at a congress held in China in 2014 [16], and fasciology as a basis of traditional medicine [17].

These studies showed that in some eras, some layers were forgotten while other layers were focused on, or vice versa, previous layers were forgotten and new layers were added. This point can be illustrated by the discrepancy in the terminology between scholars $[1,2,18]$ and our suggested system in PM [4-7]. What our concept aims to look at is that this organ is an integrated, general, and multilayer system in the human body, parts of which were predominant in any period or era. Our theory will be the first to present the mesentery as a holistic and integrative system.

\section{Embryology of the System}

The 6 layers or sections can be the Meraque layer (posterior fascia or aponeurosis of muscle interwoven with muscles of the posterior wall of the abdomen), parietal and visceral peritoneum, Massarigha (vessels), Charbi or adiposity and gut. In addition to this anatomy, PM mentioned a layer similar to the serosa (named Porz in Persian) [19].

In point of fact, our suggested system has 6 layers and is adopted (embryologically) from one area, namely the place of the pancreas and the duodenum (root region or abdominal posterior core point) [1], and it is created layer by layer during the embryonic period [unpubl. data]. This important topic has not been mentioned in the recently presented system [1]. 


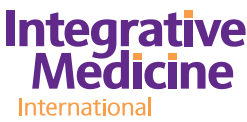

Internationa
Integr Med Int 2017;4:101-106

\begin{tabular}{l|l}
\hline DOI: $10.1159 / 000481729$ & C 2017 The Author(s). Published by S. Karger AG, Basel \\
\hline
\end{tabular} www.karger.com/imi

Avijgan et al:: Meraque/San Jiao of Eastern Medicine in Comparison with the Mesentery System Presented in Western Medicine

\section{Beginning and End of the System}

According to the article on the mesentery system [1], it seems that a suggestion about the mapping of the mesentery (M/S) is needed which may include a beginning and an end of this new system $[19,20]$. This means that a beginning and an end are necessary (similar to the cardiovascular or respiratory system). It is a shortcoming that this topic was not introduced in the article on the mesentery system [1].

Nevertheless, terms and statements, such as "discrete entity" [1], "mesenteric contiguity" [20], "it is feasible that the intestine and mesentery are contiguous from the diaphragm to the pelvic floor" [21], the mesentery and related structures [3], and the mesentery is an organ between the body system and the intestines [21], all indicate that this system may be a section of a multi-section organ which has not been described yet [unpubl. data].

\section{Evidence for Our Suggested System: Mesenteric Contiguity}

Based on the mesentery system [1], there is a separation between the mesentery, the intestines, and the posterior wall [3,19-21], but according to our suggested organ, there is a contiguity between them. These studies $[3,19-21]$ confirm our theory that the posterior wall of the abdomen and the mesentery are different parts of an organ called the Meraque organ or system.

The suggestion of a "posterior abdominal core" [22] and of the entire mesentery as an extraretroperitoneal system [23] may further confirm our theory about the M/S as an integrated organ. In fact, these studies indicate that the mesentery system $[1,22,23]$ is part of the Meraque organ that is outside the peritoneal system and is named "extraretroperitoneal" but most probably is adopted from the Meraque system in the posterior wall of the abdomen.

\section{Mesenteric Sciences}

In an evaluation of the layers of the abdominal cavity, there are numerous fasciae with different names in honor of the scholars who discovered them [1] and which are included in layers of the M/S system. The suggestion of the mesentery science is respected because it avoids a different nomination of any part of the mesentery $[1,2,18]$. Our suggestion to collect all the theories for the past 3,000-4,000 years to the present time in PM [4-7] and TCM [1-3, 18] can lead to agreement and harmony with regard to the different but distinct names that the layers of this system have $[1,19,21,24,25]$. It would be helpful to consider collaboration in the future to share new ideas, opinions, and theories in order to reach a common view.

For a deeper and basic understanding of the concept of the Meraque in PM and San Jiao in TCM, it is recommended to all those interested in the field of the mesentery that they study the articles published from 2012 to 2015 [11, 17], specifically those from a workshop in Beijing in September $2014[16,17]$.

If the M/S system (including the mesentery system) is verified and if the fact that the mesentery is only 1 of the 6 layers of this system is confirmed as a scientific finding, this will certainly be advantageous for treatment, diagnosis, pathology, surgery, and many other aspects of medicine, and many patients could be treated by an integrative method. For example, at the moment, the new method of peritoneal and rectal ozone $\left(\mathrm{O}_{3}\right)$ therapy is used for the treatment of inflammation or tumors inside or outside the gastrointestinal tract, and it seems that ozone can reach the Meraque system (via the mesentery system) and through the Meraque layer and system spread to the whole body and affect it greatly [26-28]. 


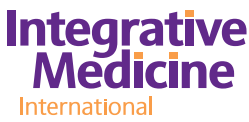

Integrative
Medicine
Integr Med Int 2017;4:101-106

\begin{tabular}{l|l} 
DOI: $10.1159 / 000481729$ & C 2017 The Author(s). Published by S. Karger AG, Basel
\end{tabular} www.karger.com/imi

Avijgan et al.: Meraque/San Jiao of Eastern Medicine in Comparison with the Mesentery System Presented in Western Medicine

At the moment, the relationship between hematologic, immunologic, endocrine, and metabolic diseases and the mesentery system is under study $[19,29]$. The mesentery system has a critical role or position in the human body and is a suitable layer reaching many areas of the body [4] so that it can be used as a method of integrative treatment.

\section{Map of the System}

Having a map of the system can be useful for physicians doing endoscopy or even for gastrointestinal tract surgeons to treat patients better, faster, more easily, and with less side effects (for example, adhesion). Although the need for a map was mentioned, no dedicated map for the mesentery system has been suggested yet [1]. For example, this map could be used as an explanation for cancer metastasis. Intestinal malignancy spreads through the lymphatic pathway [30]. Most probably, there is a contiguity between the mesentery system and the lymphatic system of the intestines. Most cancers of the large intestines can metastasize to the liver, thorax or lungs, rectum, and peritoneum [31]. The question is why and how the mesentery system can attack the thoracic cavity and its organs, while its extension goes as far as the diaphragm [1]. In addition to the blood stream, is it another route for metastasis? Our idea claims that this is possible through the middle San Jiao (abdomen) to the upper San Jiao (thorax) via the embryonic ways of the primo vascular system [11-17].

Based on the M/S theory, there is a connection between the thorax and the abdomen which is via the mesentery or Massarigha (vessels). What follows in line with our theory is the discussion about a flow chart or mapping for the M/S system, which starts from one point and continues all the way to another point [unpubl. data].

\section{Keywords}

The article on the mesentery system [1] claimed to have searched databases for several keywords, such as "mesentery," "peritoneum," "peritoneal reflection," "mesocolon," and "Toldt's fascia" (from 1958 to August 1, 2016), to find review articles [1]. We are sure that neither our published articles were considered [11-17] nor the PM and TCM ancient classical textbooks, such as the Canon of Medicine [4] and The Yellow Emperor [32,33]. Moreover, if the search had been carried out in other languages, such as Persian, and in PM and Chinese classical text books, texts on this topic would certainly have been found.

Since the publication of the article [1] in December 2016, we have recommended to the corresponding author (Dr. Coffey) to review the keywords in our articles too, where "fasciology" can be found [17] [pers. commun. in the ResearchGate profile], and also to refer to our articles which provide more information about the M/S or mesentery system [11-17].

\section{Conclusion}

The recent suggestion to define the mesentery system as a new organ of the human body is a challenging point for discussion. The mesentery system is just 1 layer of a more extended organ in PM and TCM, called system of Meraque and San Jiao, respectively. This system may be 1 important layer of the abdominal cavity but absolutely cannot be the most important layer. The Meraque and San Jiao system in PM and TCM play a critical role in the abdominal cavity and have 6 layers, which must be the subject of further studies. Of course, there are other comments for further discussion in the near future [unpubl. data]. 
Integrative Medicine

Acknowledgements

I thank Dr. Mahmoud Babayiian and Dr. Maryam Yavari for their friendly cooperation with regard to the comments on Persian medicine.

\section{Disclosure Statement}

\section{There are no conflicts of interest.}

\section{References}

1 Coffey JC, O'Leary DP: The mesentery: structure, function, and role in disease. Lancet Gastroenterol Hepatol 2016;1:238-247.

2 Coffey JC, Dillon M, Sehgal R, et al: Mesenteric-based surgery exploits gastrointestinal, peritoneal, mesenteric and fascial continuity from duodenojejunal flexure to the anorectal junction - a review. Dig Surg 2015;32: 291-300.

-3 Sehgal R, Coffey JC: Historical development of mesenteric anatomy provides a universally applicable anatomic paradigm for complete/total mesocolic excision. Gastroenterol Rep 2014;2:245-250.

4 Avicenna (Ibn-e-Sina): Anatomy of abdomen and intestines; in Canon of Medicine: Meraque and Organs (in Persian). Teheran, Sourosh Publication, 1987, part 4, pp 370-380.

5 al-Azdadi A: Meraque; in Ketab-al-Mae (in Persian). Iran University of Medical Science Publication, Research Institute for Islamic and Complementary Medicine, 1990, pp 775.

6 Arzani M: Diseases of Sefagh, Sarab and Meraque; in Tib-e Akbari (in Persian). Iran University of Medical Science Publication, Research Institute for Islamic and Complementary Medicine, 2008, vol 1, pp 904-924.

7 Aghili Khorasani M: Anatomy of abdomen; in Mualijate Aghili (in Persian). Iran University of Medical Science Publication, Research Institute for Islamic and Complementary Medicine, 2008, pp 87-95.

8 McConnell AA, Garratt TH: Abnormalities of fixation of the ascending colon: the relation of symptoms to anatomical findings. Br J Surg 1923;10:532-557.

9 Netter FH: Atlas of Human Anatomy. Philadelphia, PA, Elsevier Health Sciences, 2014.

10 Standring S: Gray's Anatomy: The Anatomical Basis of Clinical Practice. London, Elsevier Health Sciences, 2015.

11 Avijgan M, Avijgan M: Can the primo vascular system (Bong Han duct system) be a basic concept for Qi production? Int J Integr Med 2013, DOI: 10.5772/56540.

12 Avijgan M, Avijgan M: The infrastructure of the integrative human body; Qi/Dameh, Qi movement/Rouh and Zheng/Mezadj - scientific base. Int J Integr Med 2013, DOI: 10.5772/56789.

13 Avijgan M, Avijgan M: Does the primo vascular system originate from the polar body. Integr Med Int 2014;1: 108-118.

14 Avijgan M: Triple burner or San Jiao as a real or false space of body. Altern Integr Med 2014, DOI: 10.4172/23275162.S1.007.

15 Avijgan M, Avijgan M: Meraque or triple energizer (San Jiao): actual or virtual organ in traditional medicine - a hypothetical viewpoint. Integr Med Int 2015;2:9-20.

16 Avijgan M: Speech at the OMICS Group 2nd International Conference and Exhibition on Traditional and Alternative Medicine, August 25-26, Beijing, China. Published September 2014 (video). https://www.youtube. com/watch?v=yD8IiaJCgP8 (accessed July 27, 2017).

17 Avijgan M, Avijgan M: Fasciology as Base of Traditional Medicine. National Congress of Traditional Medicine at Isfahan University of Medical Sciences, December 2014 (in Persian language). http://slideplayer.com/ slide/10846356/ (accessed July 27, 2017).

18 Treves F: Lectures on the anatomy of the intestinal canal and peritoneum in man. BMJ 1885;1:580-583.

19 Coffey JC, Culligan K, Walsh LG, et al: An appraisal of the computed axial tomographic appearance of the human mesentery based on mesenteric contiguity from the duodenojejunal flexure to the mesorectal level. Eur Radiol 2016;26:714-721.

20 Culligan K, Coffey JC, Kiran RP, Kalady M, Lavery IC, Remzi FH: The mesocolon: a prospective observational study. Colorectal Dis 2012;14:421-428.

21 Culligan K, Walsh S, Dunne C, et al: The mesocolon: a histological and electron microscopic characterization of the mesenteric attachment of the colon prior to and after surgical mobilization. Ann Surg 2014;260:10481056.

22 Oliphant M, Berne AS: Computed tomography of the subperitoneal space: demonstration of direct spread of intraabdominal disease. J Comput Assist Tomogr 1982;6:1127-1137.

-23 Dodds WJ, Darweesh RM, Lawson TL, et al: The retroperitoneal spaces revisited. Am J Roentgenol 1986;147: 1155-1161. 
Avijgan et al:: Meraque/San Jiao of Eastern Medicine in Comparison with the Mesentery System Presented in Western Medicine

24 Walsh LG, Kenny BJ, El Bassiouni M, Coffey JC: Cancer arising from the remnant mucosa of the ileoanal anastomosis leading to pouchectomy. BMJ Case Rep 2016, DOI: 10.1136/bcr-2015-212802.

-25 Healy DA, Murphy SP, Burke JP, Coffey JC: Artificial interfaces ("AI") in surgery: historic development, current status and program implementation in the public health sector. Surg Oncol 2013;22:77-85.

-26 Di Filippo C, Capuano A, Rinaldi B, Luongo M, Lettieri B, Rossi F, D’Amico M: Intraperitoneal oxygen/ozone treatment decreases the formation of experimental postsurgical peritoneal adhesions and the levels/activity of the local ubiquitin-proteasome system. Mediators Inflamm 2011, DOI: 10.1155/2011/606718

-27 Sagai M, Bocci V: Mechanisms of action involved in ozone therapy: is healing induced via a mild oxidative stress? Med Gas Res 2011, DOI: 10.1186/2045-9912-1-29.

28 Agrillo A, Sassano P, Rinna C, Priore P, Iannetti G: Ozone therapy in extractive surgery on patients treated with bisphosphonates. J Craniofac Surg 2007;18:1068-1070.

29 Batra A, Heimesaat MM, Bereswill S, et al: Mesenteric fat - control site for bacterial translocation in colitis? Mucosal Immunol 2012;5:580-591.

30 Boni L, Benevento A, Dionigi G, Rovera F, Diurni M, Dionigi R: Injection of colorectal cancer cells in mesenteric and antimesenteric sides of the colon results in different patterns of metastatic diffusion: an experimental study in rats. World J Surg Oncol 2005;3:69.

31 Riihimaki M, Hemminki A, Sundquist J, Hemminiki M: Patterns of metastasis in colon and rectal cancer. Sci Rep 2016, DOI: 10.1038/srep29765.

32 Curran J: The Yellow Emperor's Classic of Internal Medicine. BMJ 2008;336:777.

33 Wang B: The Yellow Emperor's Classic of Internal Medicine - Simple Questions (Huang Di Nei Jing Su Wen). Beijing, People's Health Publishing House, 1979 (first published c. 100 BC). 